\title{
Sistem Pendukung Keputusan Pemilihan Ketua Osis Di Sekolah Menengah Atas (SMA) Negeri 1 Mulak Ulu Menggunakan Metode Analytical Hierarchy Process (AHP)
}

\author{
Risnaini Masdalipa, Debi Gusmaliza \& Riduan Syahri \\ Teknik Informatika, Sekolah Tinggi Teknologi Pagar Alam \\ E-mail: risnainipga@gmail.com
}

\begin{abstract}
Decision support system (SPK) is a computer-based system that is intended to help decision makers by utilizing certain data and models to solve various unstructured problems. From the results of research observations, it was found that the system used to elect prospective student council candidates at the State High School 1 Mulak Ulu still uses a manual selection system. This study aims to design a decision support system for OSIS chair election using the Analytical Hierarchy Process method in which OSIS chair election takes into account the criteria of intelligence, activeness, crafts as well as the vision and mission of the student council president candidates. In making this decision support system using the Programming Hypertext Preprocessor programming and Mysql database. While the system development method uses the Waterfall method with the stages of analysis, design, coding and testing. The final results obtained after being tested in the State High School 1 Mulak Ulu is a decision support system that has the ability to solve problems in the process of selecting the student council president..
\end{abstract}

Keywords: Decision support system, waterfall, Hypertext Preprocessor Programming, Analytical Hierarchy Process.

\section{Pendahuluan}

Di era globalisasi saat ini perkembangan teknologi informasi sangat pesat. Perkembangan teknologi informasi telah berevolusi dari pengolahan data elektronik (PDE) ke sistem informasi managemen (SIM) dan berlanjut pada sistem pendukung keputusan (SPK). Perkembangan teknologi informasi telah memungkinkan pengambilan keputusan dapat dilakukan dengan cepat dan cermat. Penggunaan komputer telah berkembang dari sekedar penggolahan data ataupun penyaji informasi bagi manajemen menjadi mampu untuk menyediakan pilihan-pilihan sebagai pendukung pengambilan keputusan yang dapat dilakukan oleh menajemen. Kemampuan mengambil keputusan yang cepat dan cermat akan menjadi kunci keberhasilan dalam persaingan global diwaktu mendatang (Kadarsah Suryadi, 2018, hal. 7).

Teknologi merupakan pengembangan dan aplikasi dari alat, mesin, material dan proses yang menolong manusia menyelesaikan masalah. Informasi merupakan hasil pemrosesan, manipulasi dan pengorganisasian/penataan dari sekelompok data yang mempunyai nilai pengetahuan bagi penggunanya (Sutabri, 2014).

Sistem pendukung keputusan merupakan sistem yang digunakan untuk mendukung dan membantu pihak manajemen melakukan pengambilan keputusan pada semitersrtuktur dan tidak terstruktur. Pada dasarnya konsep sistem pendukung keputusan hanyalah sebatas pada kegiatan membantu para manajer melakukan penelitian serta menggantikan posisi serta peran manajer (Wulandari, 2015, hal. 179-180). 
Analytical Hierarchy Process (AHP) adalah metode keputusan multikriteria untuk pemecahan masalah yang kompleks atau rumit, dalam sitasi tak terstruktur menjadi bagian-bagian (variabel) yang kemudian dibentuk menjadi hierarki fungsional atau terstruktur network untuk menampilkan permasalahan yang akan dipecahkan dan kemudian membangun urutan prioritas untuk alternatif melalui perbandingan berpasangan alternatif yang ada berdasarkan penilaian dari pembuat keputusan terhadap sistem Analytical Hierarchy Process (Wulandari, 2015, hal. 180-181).

Berdasarkan hasil penelitian yang dilakukan oleh (Bardansyah, 2014, hal. 21) dengan judul "sistem pendukung keputusan penentuan sekolah favorit tingkatan Sekolah Menengah Pertama swasta dengan menggunakan metode analitycal hierarchy process (AHP)" didapatkan hasil bahwa, Dalam pengambilan pemilihan Sekolah Menengah Pertama yang baik dan benar bagi siswa Sekolah Dasar yang akan melanjutan pendidikannya, banyak sekali kriteria-kriteria yang harus dilihat dari banyaknya sekolah Negeri dan sekolah Swasta yang beredar di pasaran saat ini.

Dari hasil wawancara peneliti dengan bapak Sirly Restofer Beni, S.Pd. selaku pembina OSIS 1 dan ibu Inda Setianah, S.Pd selaku pembina OSIS 2 SMA Negeri 01 Mulak Ulu didapatkan hasil bahwa pemilihan ketua OSIS saat ini masih menggunakan sistem pemilihan konvensional, dengan cara calon ketua OSIS masuk kesetiap kelas dan menyampaikan tujuan serta visi dan misi . Kemudian para siswa memilih calon ketua OSIS dengan cara menulis nomor urut calon pada kertas yang disiapkan oleh panitia pemilihan ketua OSIS. Selanjutnya tahap perhitungan suara yang diperoleh dari hasil pemilihan, calon ketua OSIS yang mendapatkan suara terbanyak akan dipilih menjadi ketua OSIS yang baru. Tapi sistem seperti ini dinilai kurang efektif dikarnakan sering terjadi kecurangan dalam pemilihan seperti siswa yang memanipulasi suara, salah satunya seperti siswa yang memilih lebih dari satu kali.

Dengan memanfaatkan teknologi yang ada diharapkan mutu dan proses pemilihan ketua OSIS dapat meningkat, pengembangan sistem pendukung keputusan pemilihan ketua OSIS memang perlu diadakan sebagai pengganti pemilihan ketua OSIS dengan metode konvensional. Berdasarkan latar belakang diatas penulis mengajukan judul "Sistem Pendukung Keputusan Pemilihan Ketua OSIS Di Sekolah Menengah Atas (SMA) Negeri 01 Mulak Ulu Menggunakan Metode Analytical Hierarchy Process (AHP)”

\section{Tinjauan Literatur}

\subsection{System}

System merupakan seperangkat elemen yang saling berinteraksi, membentuk kegiatan atau suatu prosedur yang mencari pencapaian suatu tujuan (Kadarsah Suryadi, 2018, hal. 7) Sedangkan menurut (Rosa A.S \& M. Shalahudin, 2014, hal. 2) sistem merupakan kumpulan komponen yang saling terkait dan mempunyai satu tujuan yang ingin dicapai.

Dari kajian di atas penulis menyimpulkan bahwa system merupakan suatu kumpulan komponen/elemen yang saling terkait dan saling berinteraksi membentuk kegiatan atau suatu prosedur untuk mencari pencapaian suatu tujuan.

\subsection{Sistem Pendukung Keputusan}

Sistem pendukung keputusan merupakan pengembangan lebih lanjut dari sistem informasi manajemen terkomputerisasi (Computerized management information system), 
yang dirancang sedemikian rupa sehingga bersifat interaktif dengan pemakainya (Kadarsah Suryadi, 2018, hal. 5) Sedangkan menurut (Wulandari, 2015, hal. 179-180) sistem pendukung keputusan merupakan sistem informasi interaktif yang menyediakan informasi, pemodelan dan yang pemanipulasi data. Sistem ini digunakan untuk membantu mengambil keputusan dalam situasi yang semi terstruktur dan tak terstruktur, dimana tak seorang pun tahu ssecara pasti bagaimana keputusan seharusnya dibuat.

Dari kajian di atas, penulis menyimpulkan bahwa sistem pendukung keputusan merupakan pengembangan lebih lanjut dari sistem informasi manajemen terkomputerisasi, yang dirancang sedemikian rupa sehingga bersifat interaktif dengan pemakainya. Sistem informasi interaktif yang menyediakan informasi, pemodelan dan yang pemanipulasi data.

\subsection{Analytical Hierarchy Process (AHP)}

Menurut (Permadi, 1992) AHP merupakan sebuah hirarki fungsional dengan input utamanya persepsi manusia. Dengan hirarki, suatu masalah kompleks dan tidak terstruktur dipecahkan kedalam kelompok-kelompoknya. Kemudian kelompokkelompok tersebut diatur menjadi suatu bentuk hirarki (Kadarsah Suryadi, 2018, hal. 130)

AHP merupakan metode keputusan multikriteria untuk pemecahan masalah yang kompleks atau rumit, dalam sitasi tak terstruktur menjadi bagian-bagian (variabel) yang kemudian dibentuk menjadi hierarki fungsional atau terstrktur network untuk menampilkan permasalahan yang akan dipecahkan dan kemudian membangun urutan prioritas untuk alternatif melalui perbandingan berpasangan alternatif yang ada berdasarkan penilaian dari pembuat keputusan terhadap sistem Analytical Hierarchy Process (Wulandari, 2015, hal. 180-181).

Dari kajian di atas, penulis menyimpulkan bahwa AHP merupakan sebuah metode keputusan multikriteria untuk pemecahan masalah yang kompleks atau rumit, dalam sitasi tak terstruktur menjadi bagian-bagian (variabel) yang kemudian dibentuk menjadi hirarki fungsional dengan input utamanya persepsi manusia. Dengan hirarki, suatu masalah kompleks dan tidak terstruktur dipecahkan kedalam kelompok-kelompoknya

\section{Metode Penelitian}

\subsection{Objek Penelitian}

Objek penelitian pada Sekolah Menengah Akhir Negeri 1 Mulak ulu. Waktu penelitian dimulai bulan desember 2018 sampai dengan bulan Mei 2019.

\subsection{Teknik Pengumpulan Data}

1. Wawancara, Pada tahap ini penulis mengajukan beberapa pertanyaan terhadap pihak yang terkait yaitu bagian kesiswaan atau yang mewakili guna untuk mencari informasi atau data yang diperlukan dalam pembuatan sistem.

2. Observasi, Metode ini dilakukan dengan cara mengamati secara langsung terhadap objek penelitian. Adapun data yang didapat dari hasil penelitian lapangan ini adalah mengenai proses pemilihan ketua OSIS.

3. Dokumentasi, Dokumentasi merupakan metode yang digunakan dalam mencari data - data yang berkaitan dengan penelitian. Dokumentasi yang penulis kumpulkan dalam hal ini berupa rekaman suara dan fhoto. 
4. Study pustaka, Penulis juga mengumpulkan data dari buku dan jurnal yang berhubungan dengan objek penelitian.

5. Kuisioner, Kuisioner adalah metode pengumpulan data yang dilakukan dengan memberikan lembaran yang berisi pertanyaan-pertanyaan pada Dinas Pariwisata Kota Pagar Alam

\subsection{Metode Pengembangan Sistem}

Dalam penelitian ini penulis menggunakan model pengembangan SDLC air terjun (waterfall) sering juga disebut model sekuensial linier (sequential linier) atau alur hidup klasik (classic life cyle). Model air terjun menyediakan pendekatan alur hidup perangkat lunak secara sekuensial atau terurut dimulai dari analisis, desain, pengkodean, pengujian, dan tahap pendukung (support). (Rosa A.S M. , 2016).

a. analisis, kebutuhan perangkat lunak Proses pengumpulan kebutuhan dilakukan secara intensif untuk spesifikasi kebutuhan perangkat lunak agar dapat dipahami perangkat lunak seperti apa yang dibutuhkan oleh user Spesifikasi kebutuhan perangkat lunak pada tahap ini perlu untuk di dokumentasikan.

b. Desain, Desain perangkat lunak adalah proses multi langkah yang fokus pada desain pembuatan program perangkat lunak termasuk struktur data, arsitektur, perangkat lunak, representasi antar muka, dan prosedur pengkodean. Tahap ini mentranslasi kebutuhan perangkat lunak dari tahap analisis kebutuhan kerepresentasi desain agar dapat diimplementasikan menjadi program pada tahap selanjutnya. Desain perangkat lunak yang dihasilkan pada tahap ini juga perlu di dokumentasikan.

c. Pembuatan kode program, Desain harus di translasikan kedalam program perangkat lunak. Hasil dari tahap ini adalah program komputer sesuai dengan desain yang telah dibuat pada tahap desain.

d. Pengujian, Pengujian fokus pada perangkat lunak secara dari segi lojik dan fungsional dan memastikan bahwa semua bagian sudah diuji. Hal ini dilakukan untuk meminimalisir kesalahan (error) dan memastikan keluaran yang dihasilkan sesuai dengan yang diinginkan.

e. Pendukung (support) atau pemeliharaan (maintenance), Tidak menutup kemungkinan sebuah perangkat lunak mengalami perubahan ketika sudah dikirimkan ke user. Perubahan bisa terjadi karena adanya kesalahan yang muncul dan tidak terdeteksi saat pengujian atau perangkat lunak harus beradaptasi dengan lingkungan baru. Tahap pendukung atau pemeliharaan dapat mengulangi proses pengembangan mulai dari analisis spesifikasi untuk perubahan perangkat lunak yang sudah ada, tetapi tidak untuk membuat perangkat lunak baru.

\subsection{Sistem yang Berjalan}

Analisa sistem yang sedang berjalan saat ini masih menggunakan sistem konvensional, dimana calon ketua OSIS pergi ke kelas - kelas untuk menyampaikan tujuan serta visi dan misi kepada siswa maupun dewan guru. Kemudian siswa dan dewan guru melakukan pemilihan dengan cara memilih nomor urut calon pada kertas yang telah disiapkan oleh panitia pemilihan ketua OSIS. Cara ini di nilai kurang efektif karena banyak kecurangan yang terjadi. 
Gambar 1 Sistem Yang Berjalan

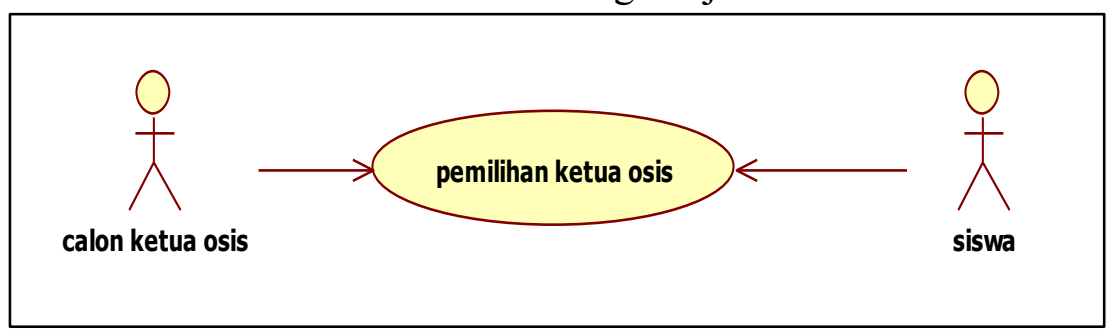

\subsection{Use Case Diagram yang di Usulkan}

Pada diagram ini yang menjadi aktor sebagai admin adalah pegawai Tata usaha atau operator sekolah dan tim penilai sebagai user. Untuk masuk kemenu home admin dan tim penilai harus login terlebih dahulu. Dalam sistem pendukung keputusan pemilihan ketua OSIS admin dapat mengelolah menu penilai, calon dan hasil sedangkan tim penilai bisa mengakses menu home, petunjuk, data calon dan mengelolah menu nilai. sedangkan calon ketua OSIS hanya mendaftarkan diri kepada admin dengan memberikan biodata kepada admin untuk diinputkan kedalam sistem.

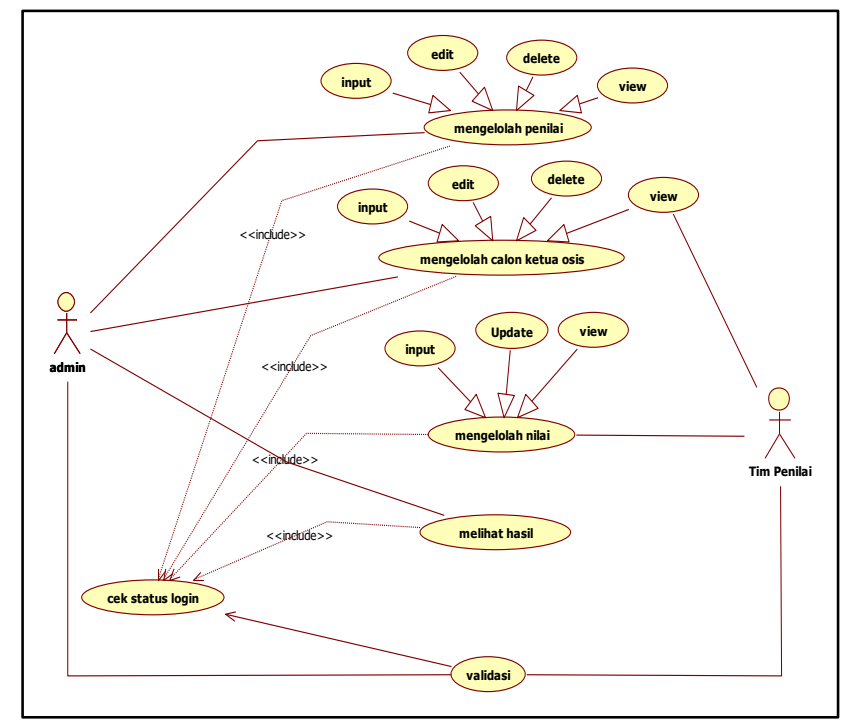

Gambar 3.4 Usecase Diagram

\section{Hasil dan Pembahasan}

\subsection{Hasil}

Pada bab ini peneliti merancang sistem pendukung keputusan pemilihan ketua OSIS pada Sekolah Menengah Atas Negeri 1 Mulak Ulu yang dapat membantu pihak Sekolah dalam pemilihan ketua OSIS.

Pada menu admin terdapat menu home, penilai, menu calon dan menu hasil penilaian. Menu penilai digunakan untuk melihat data penilai yang sudah melakukan registrasi, menu calon digunakan untuk memasukkan data calon ketua OSIS, dan menu hasil penilaian untuk menampilkan data nilai calon ketua OSIS yang telah di input kan oleh penilai.

Pada menu penilai terdapat menu home, petunjuk, data calon dan menu penilaian. Menu petunjuk menampilan petunjuk pengisian nilai pada calon ketua osis, menu calon 
menampilan data diri calon ketua OSIS, menu penilaian digunakan oleh penilai untuk memasukkan nilai calon ketua OSIS sesuai kriteria, kriteria yang dinilai kecerdasan, keaktifan, kerajinan serta visi dan misi.

\subsection{Pembahasan}

Pemilihan ketua OSIS menggunakan empat kriteria yaitu. Kecerdasan, keaktifan, kerajinan serta visi dan misi. Sistem yang dibuat menggunakan bahasa pemrograman PHP. Adapun cara untuk menjalankan aplikasi sistem pendukung keputusan pemilihan ketua OSIS SMA N 1 Mulak Ulu ini ialah dengan membuka web browser dan mengisi pencarian dengan osissmamu.000webhostapp.com yang kemudian akan menampilkan aplikas sistem pendukung keputusan pemilihan ketua OSIS SMA N 1 Mulak Ulu yang memiliki menu pilihan diantaranya yaitu Home, registrasi penilai dan Login.

\subsubsection{Menu Home}

Menu home merupakan halaman awal sebelum melakukan login, pada halaman ini terdapat menu registrasi penilai dan menu login. Menu registrasi penilai digunakan oleh siswa untuk mendaftarkan diri sebagai penilai dan menu login digunakan oleh admin dan penilai untuk masuk kedalam sistem.

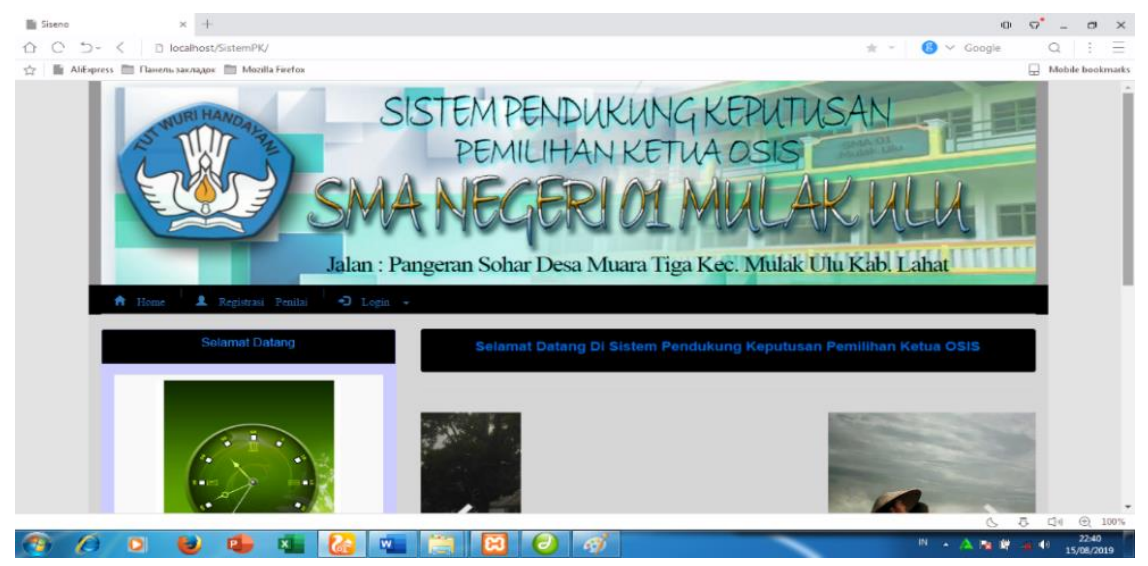

Gambar 2. Menu Home

\subsubsection{Menu Home Admin}

Menu home merupakan tampilan halaman utama admin yang terdiri dari menu home, penilai, calon, hasil penilaian dan logout. 


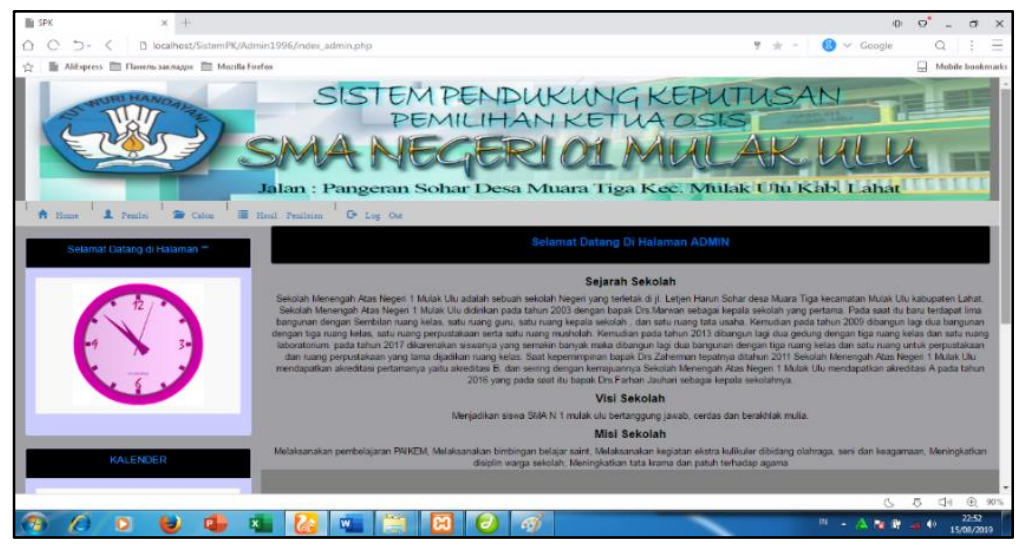

Gambar 3. Menu Home admin

\section{Kesimpulan}

Dalam penelitian skripsi ini penulis telah menguraikan beberapa tahapan yang telah dilakukan oleh peneliti dalam merancang dan membangun Aplikasi sistem Pendukung keputusan pemilihan ketua OSIS SMA N 1 Mulak Ulu, dengan ini peneliti dapat menyimpulkan beberapa hal yaitu:

1. Penelitian ini menghasilkan Sebuah Aplikasi Sistem Pendukung keputusan pemilihan ketua OSIS SMA N 1 Mulak Ulu.

2. Aplikasi Sistem Pendukung Keputusan pemilihan ketua OSIS SMA N 1 Mulak Ulu adalah sarana untuk memilih ketua OSIS yang lebih terstruktur dan dapat diakses dengan mudah.

3. Desain Interface yang menarik sangat diperlukan dalam merancang dan membangun sebuah sistem agar merasa nyaman dalam mengakses Aplikasi

4. Sasaran utama dari sistem ini adalah mempermudah pihak sekolah dalam pemilihan ketua OSIS SMA N 1 Mulak Ulu.

5. Pemilihan ketua OSIS SMAN 1 Mulak Ulu lebih efektif tanpa adanya kecurangan

\section{Referensi}

A.Hasibuan, Z. (2007:44).

Arip Aryanto, \& Tri Irianto. (2013). Pembuatan Sistem Informasi Perpustakaan Smp Muhammadiyah 7 Surakarta. Sentra Penelitian Engineering dan Edukasi, 15-16.

Bardansyah. (2014). sistem pendukung keputusan penentuan sekolah favorit tingkatan sekolah menengah pertama swasta dengan menggunakan metode analitycal hierarchy process (ahp). Pelita Informatika, 21.

Betha sidik, i. H. (2010). pemrograman web dengan html. bandung: informatika bandung.

Hendrianto, D. E. (2014). Pembuatan Sistem Informasi Perpustakaan Berbasis Website Pada Sekolah Menegah Pertama Negeri 1 Donorojo Kabupaten Pacitan. Indonesian Journal on Networking and Security, 59.

Irfan, S. (2012, 5 2). Solusi Komputer Anda. Diambil kembali dari http://trobelkomputer.blogspot.com/2012/05/axure-rp-pro-6503006.html?m=1

Janti, S. (2017). Animasi Edukasi Interaktif Tes Kemampuan Konsentrasi Dengan Permainan Tebak Warna. Jurnal Teknik Komputer Amik BSI, 107. 
Junaidi, A. (2010). Modul pembelajaran wordpress dan joomla! bandung: Modula.

Kadarsah Suryadi, I. M. (2018). sistem pendukung keputusan suatu wacana struktural idealisasi dan implementasi konsep pengambilan keputusan. bandung: Rosda.

M. Sidi Mustaqbal, Roeri Fajri Firdaus, \& Hendra Rahmadi. (2015). Pengujian Aplikasi Menggunakan Black Box Testing Boundary Value Analysis. Jurnal Ilmiah Teknologi Informasi Terapan, 34.

Rosa A.S, \& M. Shalahudin. (2014). Rekayasa Perangkat Lunak. Bandung: informatika.

Rosa A.S, M. (2016). rekayasa perangkat lunak (terstruktur dan berorientasi objek). bandung: Informatika bandung.

Setiawan, \& Rumbiak. (2017). Evaluasi Usability Website Library,.Umm.ac.id universitas multimedia nusantara. Ultima, 8.

Sibero, A. F. (2013). web programming power pack. yogyakarta: MediaKom.

Sudarmaji. (2015). Rancang Bangun Majalah Kampus Online Berbasis Web. Informatika, 54.

Sutabri, T. (2014). Pengantar teknologi informasi. yogyakarta: ANDI.

Wulandari, N. E. (2015). Sistem Pendukung Keputusan Penentu Karyawan (agen) Terbaik Menggunakan Metode Analytical Hierarchy Process (AHP). Pelita Informatika Budi Darma, 179-180.

\section{Copyrights}

Copyright for this article is retained by the author(s), with first publication rights granted to the journal.

This is an open-access article distributed under the terms and conditions of the Creative Commons Attribution license (http://creativecommons.org/licenses/by/4.0/) 